\title{
Paraoxonase-1 Phenotype and Its Relationship with Mean Platelet Volume and Oxidative Stress in Coronary Artery Disease
}

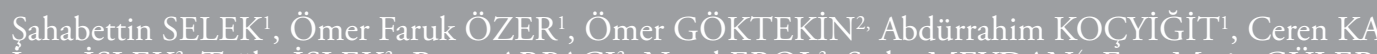 \\ Îrem IŞLEK ${ }^{3}$, Tuğba İ̧LEK ${ }^{3}$, Beyza ARPACI ${ }^{3}$, Neval EROL ${ }^{3}$, Sedat MEYDAN ${ }^{4}$, Eray Metin GÜLER \\ ${ }^{1}$ Department of Clinical Biochemistry, Bezmialem Vakif University Faculty of Medicine, Istanbul, Turkey \\ ${ }^{2}$ Department of Cardiology, Bezmialem Vakif University Faculty of Medicine, Istanbul, Turkey \\ ${ }^{3}$ Medical Student, Bezmialem Vakif University Faculty of Medicine, Istanbul, Turkey \\ ${ }^{4}$ Department of Anatomy, Bezmialem Vakif University Faculty of Medicine, Istanbul, Turkey
}

\section{ABSTRACT}

Objective: Paraoxonase-1 (PON1) 192 QR polymorphism is believed to be an important protective factor for coronary artery disease (CAD); oxidative stress plays a key role in the development of atherosclerotic CAD. Mean platelet volume (MPV) is also central to the processes, including pathophysiology of CAD and endothelial dysfunction. Thus, we aimed to determine the PON1 phenotype, MPV, and oxidative stress parameters in patients with angiographically proven $\mathrm{CAD}$ and to compare them with those in healthy subjects.

Methods: Fifty-five CAD patients were diagnosed according to the angiography results, and 37 healthy subjects were present in this study. Serum paraoxonase and arylesterase activities were spectrophotometrically measured. Phenotype distribution was evaluated by the salt-stimulated paraoxonase activity according to arylesterase activity. Oxidative stress markers were evaluated by measuring serum total oxidant status (TOS) and total anti-oxidant status (TAS) as well as oxidative stress index.

Results: In this study, the ratio of salt-stimulated paraoxonase/OSI levels (S-PON1/OSI) were lower in the CAD patients and the differences were statistically significant $(\mathrm{p}<0.05)$. Therefore, the ratio of salt-stimulated paraoxonase/MPV (S -PON1/MPV) and S- PON1/ OSI level were significantly different in the CAD patients as compared with control group $(\mathrm{p}<0.01)$.

Conclusion: Our study has suggested that S-PON1/OSI and S-PON1/MPV may play a significant role in CAD. To the best of our knowledge, the present study is the first to study the relationship among PON1 phenotype, MPV, and OSI in CAD patients. Thus, lowering of the oxidative stress and the regulation of MPV strategies may be a promising approach for the treatment of CAD.

Keywords: Paraoxonase, arylesterase, MPV, total antioxidant status, total oxidant status, oxidative stress index

\section{Introduction}

Coronary artery disease (CAD), that has a lot of complications, is one of the causes of deaths worldwide. Many researchers have shown that atherosclerosis is the major cause of CAD (1). Although many systemic events play an important role in the development of atherosclerosis, oxidative stress together with mean platelet volume (MPV) can significantly increase atherosclerosis in CAD patients (2). Atherosclerotic plaque stimulates the production of pro-inflammatory cytokines, certain interleukins, hepatic fibrinogen, and C-reactive proteins. When plaques build up in the multiple segments of coronary arteries, which supply oxygenrich blood to the myocardium, CAD generally occurs (3). The diagnosis of CAD is made by the detection of luminal stenosis during coronary angiography in most of the patients.

Many studies have shown that MPV occurs freely and is a known indicator of CAD (4); activation of platelets plays a key role in the development of atherosclerotic CAD (5). Therefore, numerous researchers have exhibited that there is a substantial association between MPV and cardiovascular risk factors such as hypertension, obesity, smoke, and diabetes mellitus. Thus, an elevated MPV induces the onset of myocardial infarction $(6,7)$. In contrast, another researcher has demonstrated that MPV is not concerned with the degree of CAD (5). However, as proposed in the previous studies, MPV may be associated with the prognostic factors of CAD, such as diabetes mellitus, hypertension, and dyslipidemia, which may affect CAD events $(8,9)$. 
PON1 is a special type of enzyme having 354 amino acids with a molecular weight of $43 \mathrm{kDa}$. It catalyzes the breakdown of paraoxan, hydrogen peroxide, organophosphates, and lipid peroxide. In the recent years, studies on PON1 have established that PON1 polymorphism might play a key role in the development of atherosclerotic $\mathrm{CAD}$, and many researchers have shown that increased PON1 activity has a special protective role in the development of atherosclerosis because of the prevention of oxidation of low-density lipoproteins (LDL) by breaking down lipid hydroperoxides in the lipoprotein $(10,11)$.

Human PON1 phenotype is classified into three polymorphisms depending on the activity of the enzyme on the substrate. Substrate activity changes as the enzyme consists of either glutamine (Q) or arginine (R) amino acids at the $192^{\text {nd }}$ position. Although $\mathrm{R}$ has a high activity, $Q$ has a lower activity. If each chromosome encodes $\mathrm{Q}$ and $\mathrm{R}$ amino acids individually, the patient would have mild activity (QR). Thus, many studies have proven that Q polymorphism has a higher risk of atherosclerosis (12).

\section{Methods}

The study was performed at the Departments of Cardiology and Clinical Biochemistry, Bezmialem Vakif University, from January 2014 to July 2014. The study group included 37 healthy persons and 55 patients diagnosed by coronary angiography. After $8-12 \mathrm{~h}$ of fasting, a $5 \mathrm{~mL}$ sample blood was taken; lipid parameters and hemogram parameters were determined from fresh serum and with EDTA tube using commercially tests (Roche/Hitachi, Basel, Switzerland). The sera were incubated at $-80^{\circ} \mathrm{C}$ until the analysis of PON1 activities and oxidative stress parameters.

In our study, we did not include patients who had history of disease, such as those with any neoplastic diseases and those who previously had angina episodes and myocardial infarction before taking any drugs.

\section{Analysis of PON1 activities}

PON1 activities were measured as the known three different activities called as the basal activity, salt-stimulated activity (presence of $\mathrm{NaCI}$ ), and arylesterase activity. Briefly, paraoxon (Sigma, St Louis, MO, USA) is used as a substrate, and the production of p-nitrophenol is measured at $412 \mathrm{~nm}$ using spectrophotometry. Generation of $\mathrm{p}$-nitrophenol $/ \mathrm{min}$ is considered as the paraoxonase activity by incorporating the molar absorptivity coefficient $\left(17100 \mathrm{M}^{-1} \cdot \mathrm{cm}^{-1}\right)$ of p-nitrophenol. Finally, paraoxonase activity was expressed as $\mathrm{U} / \mathrm{L}$ of serum (13).

Phenylacetate is used as a substrate for the measurement of arylesterase activity. As a result of hydrolyzed phenylacetate, the production of $\mathrm{phenol} / \mathrm{min}$ is calculated from its molar absorptivity coefficient $\left(1310 \mathrm{M}^{-1} \cdot \mathrm{cm}^{-1}\right)$ and the serum arylesterase activity is determined. Enzyme activities were expressed in international units $/ 1 \mathrm{~L}$ of serum (U/L). When salt-stimulated paraxonase activity is the $\mathrm{y}$ axis against the arylesterase activity on the $\mathrm{x}$ axis, the three phenotypes can be calculated (14).

\section{Analysis of total antioxidant status}

Sera TAS levels were evaluated using commercially available diagnostic kits (Rel Assay, Gaziantep, Turkey) with an auto-analyser (C-8000; Abbott, USA). Using this method, $\mathrm{Fe}^{+2} \mathrm{O}$-dianisidine complex with hydrogen peroxide generates $\mathrm{OH}^{-}$radicals by a Fenton-type reaction. This powerful, reduced ROS reacts with colorless o-dianisidine molecules at low $\mathrm{pH}$ to form yellowish-brown dianisidine radicals. O-dianisidine radicals increase the formation of the colored complex by participating in an advanced oxidation reaction. However, antioxidants that stop these oxidation reactions suppress the formation of the color. The results were provided by automated analyzers used to measure this reaction spectrophotometrically. The results were expressed as mmol Trolox equivalent/L (15).

\section{Analysis of total oxidant status}

Serum TOS levels were measured using commercially available diagnostic kits (Rel Assay, Gaziantep, Turkey) with an auto-analyzer (C-8000; Abbott, USA). Briefly, serum oxidant molecules converts ferrous ion to ferric ion. Ferric ion together with xylenol orange forms a colored complex within the acidic media. This reaction is accelerated by the glycerol molecule. The severity of the colored complex is related to the amount of oxidant molecule in the sera. $\mathrm{H}_{2} \mathrm{O}_{2}$ was used as the standard, and the results were expressed as $\mu \mathrm{mol} \mathrm{H}_{2} \mathrm{O}_{2}$ equivalent/L (16).

Calculation of oxidative stress index was performed using the following formula: OSI (arbitrary unit) $=$ TOS ( $\mu \mathrm{mol} \mathrm{H} \mathrm{H}_{2}$ equiv/L)/10×TAS (mmol Trolox equiv/L) (17). Namely, the ratio of TOS to TAS gave the oxidative stress index (OSI), an indicator of the degree of oxidative stress.

\section{Statistical analysis}

All analyses were performed using the Statistical Package for the Social Sciences (SPSS) statistical program (version 20 for Windows; SPSS, Chicago, IL, USA). The distribution of continuous variables was evaluated with a one-sample Kolmogorov-Smirnov test. Chisquare $\left(x^{2}\right)$ and Fisher's exact tests were performed for the comparison of the distribution of phenotype variables between the patients and controls; Student's t test and Mann-Whitney $U$ tests were used to compare the continuous variables. Results for continuous variables were expressed as mean \pm standard deviation, whereas categorical variables were expressed either as a number 
or percentage. A p value of $<0.05$ was considered to be statistically significant.

\section{Results}

Clinical, demographic, and laboratory parameters of the subjects are shown in Table 1 . There were no significant differences between the CAD patients and controls with respect to age and gender $(\mathrm{p}<0.05)$. Paraoxonase and arylesterase activities, salt-stimulated paraoxonase, and the ratio of S-PON1/OSI levels were significantly lower in the CAD patients; the differences were statistically significant in CAD patients compared with those in controls $(\mathrm{p}<0.05$ for all). There was also a significant difference in the ratio of S-PON1/MPV between control group and the patients $(\mathrm{p}<0.05)$.

\section{Discussion}

In our study, we investigated the hypothesis that decreased PON1 activity, ratio of S-PON1/OSI, and PON1/MPV may play a key role in the pathogenesis of CAD. We observed that CAD patients had a lower level of serum paraoxonase and arylesterase activities as well as decreased ratio of S-PON1/OSI and PON1/MPV when compared with the healthy subjects (Table 2). As we mentioned before, many studies have shown that humans with the PON1 192 Q phenotype are more prone to $\mathrm{CAD}$ than those with the $\mathrm{R}$ phenotype (18). The $192^{\text {nd }}$ position of amino acid has two polymorphisms that are known as R (high activity) and Q (low activity). Thus, human polymorphism can be separated into the following three phenotypes: QQ (low activity), QR (intermediate activity), and RR (high activity) $(12,19)$.

Actually, many researchers have demonstrated that low PON1 activity is associated with CAD because LDL oxidation is not prevented. PON1 is also an antioxidant enzyme that prevents the oxidation of LDL as well as HDL (20). We also observed a statistical difference in PON1 activities between CAD patients and the control

Table 1. Demographic and social parameters in CAD patients and controls

\begin{tabular}{|c|c|c|c|}
\hline Parameters & CAD $(n=55)$ & Controls $(n=37)$ & $\mathbf{p}$ \\
\hline Age (years) & $60 \pm 10$ & $56 \pm 12$ & Ns \\
\hline $\operatorname{Sex}(M / F)$ & $39 / 16$ & $26 / 11$ & Ns \\
\hline $\mathrm{HDL}-\mathrm{C}(\mathrm{mg} / \mathrm{dL})$ & $29 \pm 7$ & $33 \pm 8$ & Ns \\
\hline LDL-C (mg/dL) & $120 \pm 39$ & $125 \pm 45$ & Ns \\
\hline $\mathrm{TC}(\mathrm{mg} / \mathrm{dL})$ & $180 \pm 45$ & $192 \pm 54$ & Ns \\
\hline $\mathrm{TG}(\mathrm{mg} / \mathrm{dL})$ & $138 \pm 71$ & $154 \pm 95$ & Ns \\
\hline \multicolumn{4}{|c|}{$\begin{array}{l}\text { CAD: coronary artery disease; BMI: body mass index; HDL-C: high-density } \\
\text { lipoprotein-cholesterol; LDL-C: low-density lipoprotein-cholesterol; TC: } \\
\text { total cholesterol; TG: triglyceride; values are mean } \pm S D \text {; ns: non-significant }\end{array}$} \\
\hline
\end{tabular}

Table 2. Comparison of parameters in patients diagnosed with $C A D$ and the control group*

\begin{tabular}{|c|c|c|c|}
\hline Parameters & CAD $(n=55)$ & Controls (n=37) & $\mathbf{p}$ \\
\hline PON1 (U/L) & $195 \pm 147$ & $271 \pm 168$ & $<0.05$ \\
\hline S-PON1 (U/L) & $432 \pm 306$ & $617 \pm 347$ & $<0.05$ \\
\hline Arylesterase (kU/L) & $315 \pm 47$ & $341 \pm 59$ & $<0.05$ \\
\hline OSI & $0.76 \pm 0.16$ & $0.70 \pm 0.19$ & Ns \\
\hline S-PON1/OSI & $580 \pm 399$ & $938 \pm 603$ & $<0.01$ \\
\hline $\begin{array}{l}\text { S-PON1/MPV } \\
\text { TAS (mmol }\end{array}$ & $43 \pm 31$ & $65 \pm 35$ & $<0.01$ \\
\hline $\begin{array}{l}\text { Trolox equiv } / L) \\
\text { TOS ( } \mu \mathrm{mol}\end{array}$ & $2.9 \pm 0.4$ & $3.0 \pm 0.5$ & Ns \\
\hline $\mathrm{H}_{2} \mathrm{O}_{2}$ equiv/L) & $22.3 \pm 3.6$ & $20.9 \pm 3.8$ & Ns \\
\hline PLT $\left(\times 10^{3} / \mathrm{L}\right)$ & $220 \pm 60$ & $225 \pm 65$ & Ns \\
\hline MPV (FL) & $10 \pm 0.8$ & $9 \pm 0.8$ & Ns \\
\hline $\begin{array}{l}\text { *The data are presente } \\
\text { CAD: coronary artery d } \\
\text { index; MPV: mean plate } \\
\text { total oxidant status; PL }\end{array}$ & $\begin{array}{l}\text { d as mean } \pm S D ; N \\
\text { sease; } P O N 1: \text { par } \\
\text { let volume; TAS: } \\
\text { r: platelet count }\end{array}$ & $\begin{array}{l}\text { non-significant } \\
\text { oxonase-1; OSI: oxidat anti-oxidant status }\end{array}$ & $\begin{array}{l}\text { ve stress } \\
\text { TOS: }\end{array}$ \\
\hline
\end{tabular}

group (Table 2). Some researchers demonstrated that PON1R is more protective against CAD than the $Q$ phenotype (21), as we expected (Figure 1). We observed that TOS was higher in CAD patients than in controls, although there was no statistical significance. However, S-PON1/OSI was lower in CAD patients compared to controls. Thus, decreased S-PON1/OSI may, in part, be prone to the development of atherosclerosis in CAD patients because of increased susceptibility to lipid peroxidation (Figure 2, 3). Thus, it seems reasonable that S-PON1/OSI ratio represents the function of coronary artery. Here, we demonstrated that S-PON1/OSI ratio might be an independent risk factor associated with CAD patients, while lipid profile and other conventional risk factors did not show such relationships. We have also demonstrated that MPV was elevated in CAD patients but there was no statistically significant difference between patients and controls (Table 2). However, we observed that the ratio of S-PON1/MPV is higher in CAD patients than that in controls.

Many scientists have demonstrated that MPV levels were significantly higher in patients with CAD than those in controls $(22,23)$. Platelets that have high MPV are enzymatically and metabolically active and release more cytokines and mediator molecules. These molecules can lead to the development of atherosclerotic plaques. Hence, many mediators that are expressed by activated platelets may contribute to coronary atherosclerosis in $\mathrm{CAD}$ patients. The relationship between atherosclerosis and high MPV could be explained by both the increased 


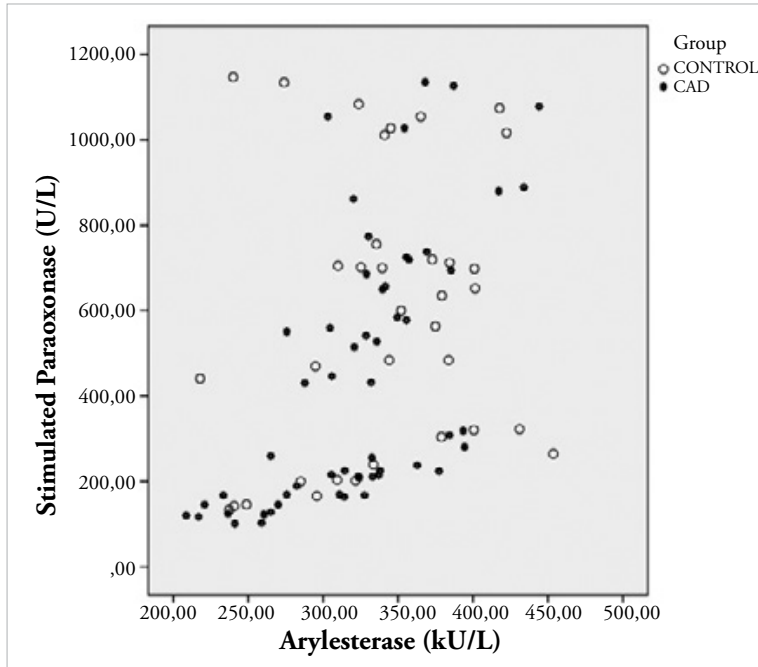

Figure 1. Distribution of Phenotype in patients and control groups

number of platelets and platelet aggregation in coronary arterioles $(23,24)$.

In the light of the findings of this study, PON1/MPV seems to be an independent predictor for CAD patients. We also suggest that S-PON1/OSI and PON1/ MPV can be considered to be the new risk factors for atherosclerotic CAD. Reduction of PON1 activities may also increase the development of atherosclerosis in CAD patients. Thus, investigation is required to explain the possible mechanisms underlying the relationship between paraoxonase phenotype and MPV.

Ethics Committee Approval: Ethics committee approval was obtained.

Informed Consent: Written informed consent was obtained from patient/ patients who participated in this study.

Peer-review: Externally peer-reviewed.

Author Contributions: Concept - Ş.S., Ö.F.̈̈., Ö.G., A.K., C.K., İ.İ., T.İ., B.A., N.E., S.M., E.M.G.; Design - Ş.S., Ö.F.Ö., Ö.G., A.K., C.K., İ.İ., T.İ., B.A., N.E., S.M., E.M.G.; Supervision - Ş.S., Ö.F.Ö., Ö.G., A.K., C.K., İ.I., T.İ., B.A., N.E., S.M., E.M.G.; Funding - Ş.S., A.K., Ö.G.; Materials - Ş.S., Ö.G.; Data Collection and/or Processing - C.K., İ.I., T.I.., B.A., N.E., Ş.S.; Analysis and/or Interpretation - Ş.S., A.K., Ö.G.; Literature Review - C.K., İ.İ., T.İ., B.A., N.E., Ş.S.; Writer - Ş.S.; Critical Review - Ş.S.

Conflict of Interest: The authors declared no conflict of interest.

Financial Disclosure: Bezmialem Vakif University Scientific Research Projects Unit (Project No: 9.2014/3)

\section{References}

1. Beckman JA, Creager MA, Libby P. Diabetes and atherosclerosis: epidemiology, pathophysiology, and management. JAMA 2002; 287: 2570-81. [CrossRef]

2. Gasparyan AY, Ayvazyan L, Mikhailidis DP, Kitas GD. Mean platelet volume: a link between thrombosis and inflammation? Curr Pharm Des 2011; 17: 47-58. [CrossRef]

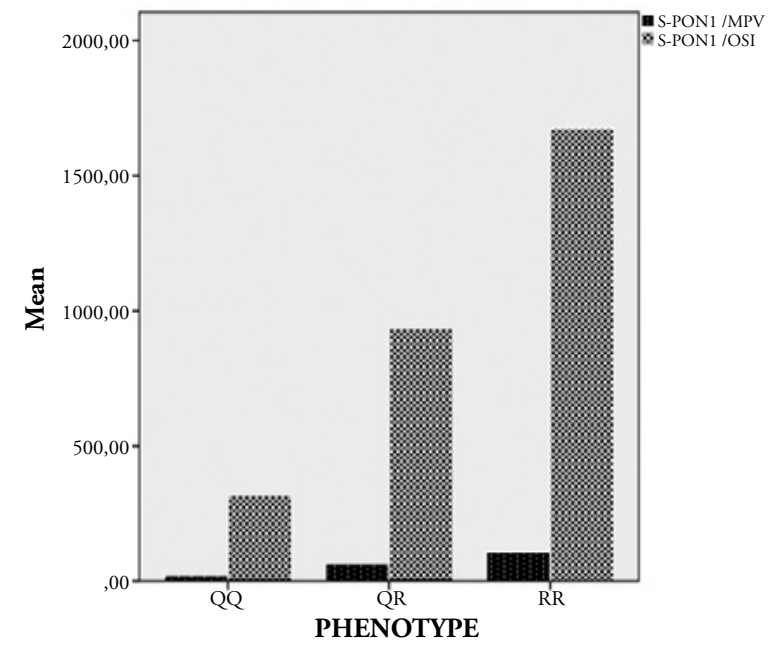

Figure 2. Relationship with between Phenotype distribution and ratio of S-PON1/MPV, S-PON1/OSI.

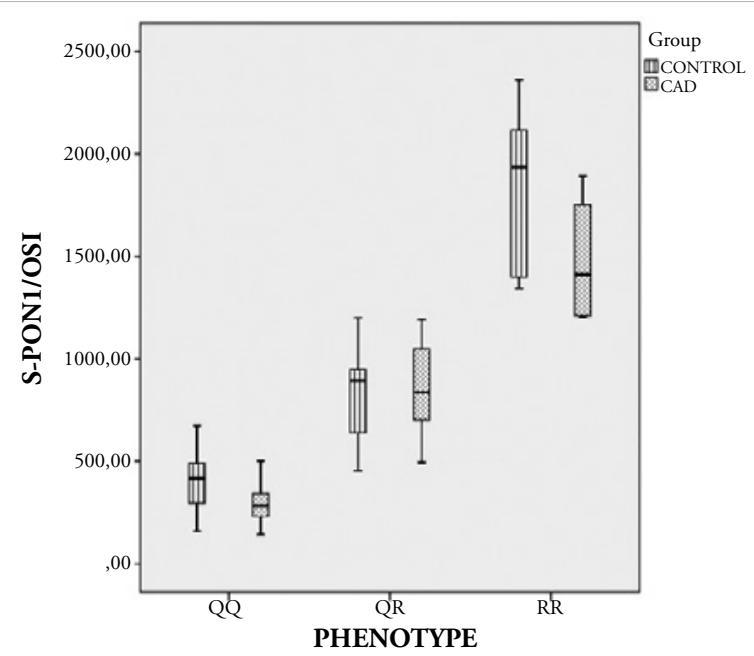

Figure 3. Relationship with between Phenotype distribution and ratio of S-PON1/OSI in patients and control group

3. Birdane A, Yazici HU, Aydar Y, Nadir A, Şenol U, Tasal A, et al. Relationship between significant coronary artery disease and coronary artery anomalies. Turk J Med Sci 2013; 43: 430-5. [CrossRef]

4. Ma H, Lin H, Hu Y, Li X, He W, Jin X, et al. Mean platelet volume in relation to carotid atherosclerosis in normotensive, euglycemic, and normolipidemic Chinese middle-aged and elderly adults. Angiology 2014; 65: 512-8. [CrossRef]

5. De Luca G, Santagostino M, Secco GG, Cassetti E, Giuliani L, Franchi E, et al. Mean platelet volume and the extent of coronary artery disease: results from a large prospective study. Atherosclerosis 2009; 206: 292-7. [CrossRef]

6. Hekimsoy Z, Payzin B, Örnek T, Kandoğan G. Mean platelet volume in Type 2 diabetic patients. J Diabetes Complications 2004; 18 : 173-6. [CrossRef]

7. Nadar SK, Blann AD, Kamath S, Beevers DG, Lip GY. Platelet indexes in relation to target organ damage in high-risk hypertensive patients: a substudy of the Anglo-Scandinavian Cardiac Outcomes Trial (ASCOT). J Am Coll Cardiol 2004; 44: 415-22. [CrossRef]

8. Nadar S, Blann A, Lip G. Platelet morphology and plasma indices of platelet activation in essential hypertension: effects of amlodipine-based antihypertensive therapy. Ann Med 2004; 36: 552-7. [CrossRef] 
9. Coban E, Bostan F, Ozdogan M. The mean platelet volume in subjects with impaired fasting glucose. Platelets 2006; 17: 67-9. [CrossRef]

10. Mirdamadi HZ, Sztanek F, Derdak Z, Seres I, Harangi M, Paragh G. The human paraoxonase-1 phenotype modifies the effect of statins on paraoxonase activity and lipid parameters. Br J Clin Pharmacol 2008; 66: 366-74. [CrossRef]

11. Durrington P, Mackness B, Mackness M. Paraoxonase and atherosclerosis. Arterioscler Thromb Vasc Biol 2001; 21: 473-80. [CrossRef]

12. Ruiz J, Morabia A, Blanche H, James R, Garin MB, Charpentier G, et al. Gln-Arg192 polymorphism of paraoxonase and coronary heart disease in type 2 diabetes. Lancet 1995; 346: 869-72. [CrossRef]

13. Takci Z, Bilgili S, Karadag A, Kucukoglu M, Selek S, Aslan M. Decreased serum paraoxonase and arylesterase activities in patients with rosacea. J Eur Acad Dermatol Venereol 2014; 29: 367-70. [CrossRef]

14. Selek S, Cosar N, Kocyigit A, Erel O, Aksoy N, Gencer M, et al. PON1 activity and total oxidant status in patients with active pulmonary tuberculosis. Clin Biochem 2008; 41: 140-4. [CrossRef]

15. Erel O. A novel automated method to measure total antioxidant response against potent free radical reactions. Clin Biochem 2004; 37: 112-9. [CrossRef]

16. Erel O. A new automated colorimetric method for measuring total oxidant status. Clin Biochem 2005; 38: 1103-11. [CrossRef]

17. Aycicek A, Erel O. Total oxidant/antioxidant status in jaundiced newborns before and after phototherapy. J Pediatr (Rio J) 2007; 83: 319-22. [CrossRef]
18. Ginsberg G, Neafsey P, Hattis D, Guyton KZ, Johns DO, Sonawane B. Genetic polymorphism in paraoxonase 1 (PON1): Population distribution of PON1 activity. J Toxicol Environ Health B Crit Rev 2009; 12: 473-507. [CrossRef]

19. Jarvik GP, Rozek LS, Brophy VH, Hatsukami TS, Richter RJ, Schellenberg GD, et al. Paraoxonase (PON1) phenotype is a better predictor of vascular disease than is PON1192 or PON155 genotype. Arterioscler Thromb Vasc Biol 2000; 20: 2441-7. [CrossRef]

20. Seres I, Paragh G, Deschene E, Fulop T, Khalil A. Study of factors influencing the decreased HDL associated PON1 activity with aging. Exp Gerontol 2004; 39: 59-66. [CrossRef]

21. Kotur-Stevuljevic J, Bogavac-Stanojevic N, Jelic-Ivanovic Z, Stefanovic A, Gojkovic T, Joksic J, et al. Oxidative stress and paraoxonase 1 status in acute ischemic stroke patients. Atherosclerosis 2015; 421: 192-8. [CrossRef]

22. Murat SN, Duran M, Kalay N, Gunebakmaz O, Akpek M, Doger $\mathrm{C}$, et al. Relation between mean platelet volume and severity of atherosclerosis in patients with acute coronary syndromes. Angiology 2013; 64: 131-6. [CrossRef]

23. Ozkan B, Uysal OK, Duran M, Sahin DY, Elbasan Z, Tekin K, et al. Relationship between mean platelet volume and atherosclerosis in young patients with ST elevation myocardial infarction. Angiology 2013; 64: 371-4. [CrossRef]

24. Karan A, Güray Y, Güray U, Demirkan B, Astan R, Baysal E, et al. Mean platelet volume and the extent of coronary atherosclerosis in patients with stable coronary artery disease. Turk Kardiyol Dern Ars 2013; 41: 45-50. [CrossRef] 